INDEPENDENT JOURNAL OF MANAGEMENT \& PRODUCTION (IJM\&P)

http://www.ijmp.jor.br

v. 12, n. 4, May-June 2021

ISSN: 2236-269X

DOI: 10.14807/ijmp.v12i4.1345

\title{
CLEANER PRODUCTION ALTERNATIVES FOR A COSMETICS INDUSTRY IN SOUTHERN BAHIA
}

\author{
Maricélia Almeida dos Santos \\ Universidade Federal do Sul da Bahia, Brazil \\ E-mail: mariceliaalmeida19@gmail.com \\ Bruna Borges Soares \\ Universidade Federal do Sul da Bahia, Brazil \\ E-mail: soaresborges.b@gmail.com \\ Lucas Farias de Sousa \\ Universidade Estadual de Santa Cruz, Brazil \\ E-mail: eng.sousalucas@gmail.com
}

Edmar Costa Alves

Instituto Federal de Educação, Ciência e Tecnologia de Rondônia, Brazil

E-mail: edmar.meta@gmail.com

Submission: 5/16/2020

Revision: 7/3/2020

Accept: 7/14/2020

\section{ABSTRACT}

The production of cosmetics has received attention due to the high demand for beauty and personal care items. In contrast, negative interferences are related to this sector, from obtaining the raw material to the final disposal of packaging. This study aimed to identify critical points and opportunities for environmental improvements in the cosmetic industry in southern Bahia based on the principles of Cleaner Production (CP). The methodology used was based on the principles of Cleaner Production proposed by UNEP/UNIDO and the data collection was carried out through on-site visits including consultation to the company's files. Also was realized a cross-analysis of the study results with elements identified in the literature that allowed the identification and discussion of CP opportunities, as well as suggestions for improvements to the critical points found. The consumption of raw materials and the generation of solid waste were aspects with more critical points. The refuse of material and inadequate destination of solid residues (oil drums, pallets, among others), as well as the replacement of raw materials by alternative and renewable sources, reverse logistics implementation and redesign of the packaging process were the opportunities for improvement aimed. 
DOI: $10.14807 /$ ijmp.v12i4.1345

Other critical points were related to the consumption of water, energy and generation of atmospheric gases. The suggested proposals can promote the reduction in material waste, rework and productivity gains. In addition, they serve as a subsidy and direct environmentally actions more appropriate, once the "clean beauty industry" seems to be a growing trend and a business opportunity, as well as can be requested by environmentally responsible customers in some moments.

Keywords: reduction at source; opportunities for improvement; environmental management; environmental impacts

\section{INTRODUCTION}

Cosmetics products are defined as a combination of substances that have direct contact with external parts of the human body or the teeth, which have the main purpose of cleaning, perfuming, beautifying, protecting, keeping them in good condition or eliminating body odors (Cosmetics Europe, 2019a). Sector cosmetics covers a wide variety of products in seven categories - oral hygiene, skincare, sun protection, haircare, decorative cosmetics, bodycare, and perfumes.

In the cosmetics industry, it has expanded worldwide and received significant attention from consumers. In Brazil, the personal hygiene, perfumery and cosmetics sector (HPPC) has grown over the past ten years, consolidating the country in the fourth world position in consumption and directly contributing to the country's wealth generation (ABIHPEC, 2019).

The frequent use and hard demand suggest that these products have become an essential part of our daily lives, and related production processes must be properly evaluated and managed to avoid environmental damage. Although it presents relevant importance, the activities of this sector can negatively interfere in the environment. According to VargasGonzalez et al. (2019), in the cosmetic sector, there is a great depletion of natural resources from the extraction process of the raw material for manufacture until its post-consumption.

To obtain cosmetics, a considerable amount of raw materials is required. Due to its complex formulation, each cosmetic line has different characteristics adjusted for its purpose (Galembeck and Csordas, 2011). The selection of the raw material is an important element in this production, as obtaining it can cause significant environmental impacts. In addition to resource consumption, other impacts may also be associated such as packaging, distribution, and consumption reaching the post-consumption phase (Bom et al., 2019). 
INDEPENDENT JOURNAL OF MANAGEMENT \& PRODUCTION (IJM\&P)

http://www.ijmp.jor.br

v. 12, n. 4, May-June 2021

ISSN: 2236-269X

DOI: 10.14807/ijmp.v12i4.1345

New proposals emerge in order to improve the environmental situation, looking for tools that induce innovation in their business models (Bai et al., 2015). Among the environmental management tools used, there is the Cleaner Production (CP) (Matos et al., 2018). The CP emphasizes the implementation of best environmental practices in manufacturing processes through the continuous application of a preventive environmental strategy integrated with processes, products and services, to increase efficiency and reduce risks to humans beings, as well as the environment (UNEP, 1994).

The improvement in product quality which reduces the consumption of raw materials and inputs, as well as minimizing the generation of residues are among the great results achieved. The utility of all models and sizes have been adopted this alternative, enabling a great growth of the practice over the years, due to improvements both in technology, processes and organizational (Matos et al., 2018).

For the implementation of Cleaner Production, it is necessary to adopt some actions, which can vary in three levels of intervention whose goal is to prioritize activities (Barbosa, 2018) with a focus on minimization and reuse of waste and atmospheric emissions. Those actions may include level 1, with a focus on reducing waste at the source (Denham et al., 2015); level 2 through actions aimed at internal recycling (such as energy and advanced materials recovery and/or its own production process); besides level 3, which include external recycling (waste recycling by other companies as raw materials), and biogenic cycles with the reintegration of organic matter into the environment by a natural process (Filho et al., 2019).

In view of the expansion of the cosmetics and personal care sector over the years and the environmental interferences caused, it is necessary to implement actions that can positively contribute to environmental sustainability in the production stage. This study aims to identify the opportunities for applying Cleaner Production in the cosmetics industry in Southern Bahia that can guide decision-makers implementing environmental improvements, in addition to pointing out the benefits that such opportunities can bring for the organization.

\section{DATA AND METHODOLOGY}

\subsection{Research method and data gathering procedure}

The methodology has been based on the principles proposed by UNEP/UNIDO for Cleaner Production. In this way, information was collected on each unitary process that is included within the limits of the study, as well as input and output relevant. 
DOI: 10.14807/ijmp.v12i4.1345

Data collection occurred from July 2019 to February 2020 through on-site visits and consultation of the organization's files. A cosmetics factory was used as a case study.

The main information recorded was about the consumption of natural resources and secondary materials, energy consumption (electric and fuel) besides data on the generation of liquid effluents and solid waste.

The cross-analysis of the case study results with elements identified in the literature allowed the identification and discussion of CP opportunities, as well as in the suggestions for improvements to the critical points found. An Environmental Technical Guide (CETESB, 2012) was used as supporting material.

\subsection{Location and characteristics of the case study}

The cosmetics factory where the case study was conducted is located in the south of Bahia. The region is administratively composed of 26 cities and comprises one of the main economic centers of the state (SEI, 2015). The company is responsible for processing capillary and body products and classified as the small to medium polluting potential (CEPRAM, 2018).

The production occurs for demand. On average are manufactured 1.4 million products per year between oils and creams. Its catalog includes 5 categories of products subdivided into hair and skincare.

The skincare line comprises body oils. These are suitable to nourish and moisturize the skin. The hair care line comprises oils, tip repairman, styling ointment and combing cream. These products are indicated for nutrition, hydration, repair tips of the fragile, as well as shaping and aligning the threads. The products also vary with the essences (aromatic substances) and colorants used, resulting in 21 different types of products.

\section{RESULTS AND DISCUSSION}

\subsection{Description of the production process}

In general, in order to obtain finished products, the production process is subdivided into the reception and stock of raw material stages; separation and preparation; mixture; filling and primary packaging; secondary packaging; final product storage, and shipping (Figure 01). Other different steps take place in the shaping ointment production and tip repairman (e. g. heating the material).

The production process begins with the arrival of the raw materials. The mineral oil in nature, the main raw material, is received in 200-liter plastic drum containers. This material 
ISSN: 2236-269X

DOI: 10.14807/ijmp.v12i4.1345

remains in these recipients until the moment of use. Other inputs are taken to the stock, where they are stored on shelves and pallets. This step also includes the receipt of packaging and labels, as well as storage of the packaging after labeled. The labeling occurs in an automated way, in the case of packing capillary oil, and manually in all other cases.

The process of making skin and hair oils is similar, both involve the use of mechanical processes. The mineral oil is sent to the production area using an electric motor. First, the raw material goes through the filtration process to remove impurities (small solid particles of dirt), then, the filtered raw material follows to the mixing tank, where other items are added (colorants and essences). The difference between the two processes is that in the production of body oil one wetting agent is added, which is not added in the capillary oil.

To obtain the tip repairman and styling ointment, occur in addition to mechanical processes, thermal processes. Other materials are also used to manufacture these products such as beeswax, petroleum jelly and coagulants. These materials are mixed and heated in LPG powered boiler at $80^{\circ} \mathrm{C}$, then are naturally cooled.

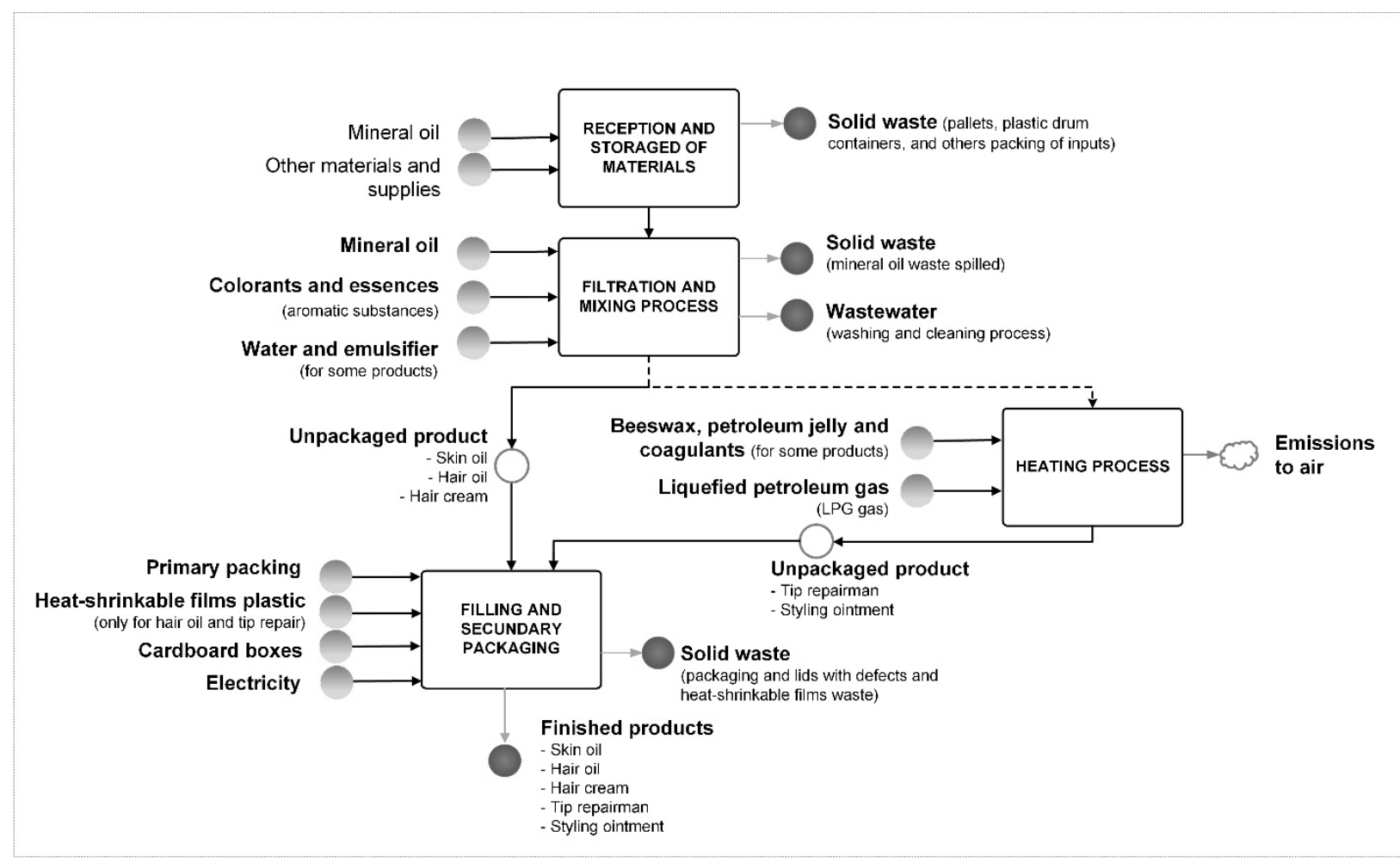

LEGEND:

UNIT PROCESS INPUT INTERMEDIATE OUTPUT Emissions

Permanent flow between Unit Processes [occurs in all products]
Conditional flow between Unit Processes [occurs in some products]

Output flow (products and emissions)

Figure 01: Flowchart of the production process. 
DOI: 10.14807/ijmp.v12i4.1345

The beeswax and petroleum jelly give the styling ointment a pasty consistency that at room temperature becomes a solid product. The coagulant is used to make the tip repairer. The substance causes a change in the viscosity of the mixture, giving it a higher density, without changing its physical state. In these products are added essences and colorants that give color, aroma and other properties as well.

The hair cream manufacturing is realized manually at room temperature. In addition to mineral oil, colorants and essences also water and an emulsifier are used in this process. The emulsifier, an important substance for hair cream, allows the water and oil (immiscible substances) to mix, forming a creamy product. This stage comprises the homogenization of phases aqueous and fatty phases.

After the materials are ready they are filled in recipient with different dimensions (skin and body oil in 60 and $100 \mathrm{ml}$ packing, styling ointment in 40 g packing, tip repairer oil in recipients of 30ml and hair cream in 90g packing). Secondary packaging and storage steps are common to all products. They can be grouped with heat-shrinkable films plastic or in cardboard boxes and then they are sent to the finished goods stock.

The cosmetic products obey the detailed composition and labeling requirements (BRASIL, 1976). Thus, the activity is regulated by Anvisa, a Brazilian sanitary surveillance agency, that regulates, controls and inspects products, substances and services of interest to health, which includes cosmetic products.

\subsection{Environmental aspects and impacts}

\section{- Consumption of raw materials and other inputs}

Mineral oil is used in all production lines (annual consumption of approximately 12,000 liters). In addition, other inputs are also consumed as coagulants, aromatic essences, colorants, materials used in the filling and packaging stages (labels; primary packaging, heat-shrinkable films and cardboard boxes). Input suppliers are located in other cities, inside and outside the state boundaries, and the acquisition is carried out according to stock low, as demand.

\section{- Water consumption}

Water consumption in the production of cosmetics is small, except for skin creams production. On average the annual consumption of water is 15,000 liters and the use happens mainly in the hygiene and cleaning of equipment, washing the floors and walls of the factory, 
DOI: 10.14807/ijmp.v12i4.1345

as well as in the daily use of contributors (personal hygiene and toilets). The water supply is carried by a municipal public company.

\section{- Energy consumption}

The electricity is used in transporting the main raw material (performed with electric engine), in stirring of the mixer (mixing tank), automated labeling process, filling and packaging processes, as well as ambient lighting and ventilation. The annual consumption is $15,217 \mathrm{kWh}$ and supply is carried out by a concessionaire.

Most processes realized are carried out at room temperature. Those that require heating are done for a short period of time and the fuel used is liquefied petroleum gas (LPG). On average are used 52 cylinders per year ( $270.4 \mathrm{~m}^{3}$ of gas).

\section{- Generation of solid waste, wastewater and emissions}

The main solid waste generated is unused packaging and lids, the plastic drum containers of mineral oil, pallets, cardboard, recipients of input, plastic refuse and heatshrinkable film shavings, labels, as well as boxes used for secondary packaging. Products outside specification or expiration date and waste mineral oil (spilled oil into processes) also can be waste generated eventually.

The generation of packaging waste is one of the most significant impacts in the sector, once a large amount of packaging and lids with defects are discarded (approximately $10 \%$ of the total acquired). Linked to this, there is also a loss of labels unusable when the packings are rejected.

In the secondary packaging stage, there is a great loss of heat-shrinkable films. The machine that performs this process does not scale the amount of plastic efficiently, generating large amounts of shavings.

With regard to wastewater, there is no treatment plant at the factory. The effluent generated in the washing process (floors, walls, utensils and sanitary effluents) are sent directly to the municipal treatment sewer system.

There is also the emission of odorous substances in the entire production process, from the handling of raw materials and inputs to the packaging process. The production area does not have a ventilation system to reduce the concentration of the air contaminants (dilution ventilation). There is also the greenhouse gas emission direct occurs in the process that requires heating from fuel LPG gas. 
INDEPENDENT JOURNAL OF MANAGEMENT \& PRODUCTION (IJM\&P)

http://www.ijmp.jor.br

v. 12, n. 4, May-June 2021

ISSN: 2236-269X

DOI: 10.14807/ijmp.v12i4.1345

\subsection{Clean production application opportunity}

In the company, there is no control over environmental aspects. For each of them, were linked opportunities for Cleaner Production (Table 01). The actions were classified according to the level of intervention: minimization of waste and/or consumption of resources at source (level 1), internal recycling (level 2) or reuse of waste (level 3), with a focus on external recycling. The theoretical basis for each action (consulted literature) is also present.

Table 01: Cleaner Production Application Opportunity

\begin{tabular}{lcc}
\hline Linked opportunities & $\begin{array}{l}\text { Consulted } \\
\text { literature }\end{array}$ & $\begin{array}{c}\text { Intervention } \\
\text { level }\end{array}$
\end{tabular}

Consumption of raw materials and other inputs

- Control on receipt of raw materials, based on quality tests and definition of acceptable levels.

CETESB (2012)

- Use of alternative raw materials based on plants and vegetable oils. _ Yara-Varón et al. (2017)

- Partnerships with local suppliers also committed to environmental Carvalho and issues.

Barbieri (2012)

- Improvement in the purchasing and sales system.

Bom et al. (2019)

- Prioritize the purchase of raw materials and inputs produced with recyclable or recycled materials.

Carvalho and

Barbieri (2012)

Level 1-

Reduction at

source

- Organize raw materials and supplies based on the FEFO (First Expired, First Out) system to avoid discarding them by maturity,

CETESB (2012) without use.

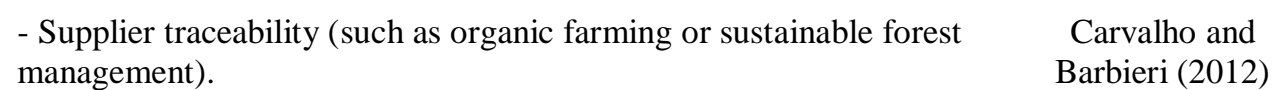

- Training employees on the handle and transfer materials (in order to avoid product damage, loss of materials, accidents with chemicals), and consequently, more generation of solid waste and

CETESB (2012) wastewater.

\section{Energy consumption}

- Replacement of energy conventional sources by alternative, more sustainable options (when possible).

COSMOS-standard

(2019); Cosmetics

Europe (2019b)

- Installation of lamps with presence sensors to avoid unnecessary energy consumption.

COSMOS-standard (2019)

- The shutdown of equipment and machinery when not in use.

CETESB (2012)

Level 1Reduction at source

- Acquisition of a more modern sealing machine. This will increase the efficiency of the packaging process, reducing the amounts of shavings (solid waste), as well as reducing the consumption of CETESB (2012) electricity. 
INDEPENDENT JOURNAL OF MANAGEMENT \& PRODUCTION (IJM\&P)

http://www.ijmp.jor.br

v. 12, n. 4, May-June 2021

ISSN: 2236-269X

DOI: 10.14807/ijmp.v12i4.1345

\section{Water consumption}

- Collection of rainwater for washing walls and floors and reuse in toilets and processes that do not request treatment.

Nunes et al. (2018)

- Installation of flow meters for identified the most critical points/processes in relation to water consumption, in addition to

CETESB (2012)

Level 1possible leaks.

CETESB (2012)

- Training employees in Good Manufacturing Practice (GMP).

Xanthos and Walker

- Employees' awareness to reduce the consumption of water and (2017) cleaning products.

\section{Wastewater generation}

- Employees’ awareness to reduce the consumption of water and Xanthos and Walker cleaning products.

- Programmed production by color criteria (starting with the lightest colors and moving to the darkest tones). This will promote a reduction in cleaning practices between batches and, consequently, a reduction in the consumption of water, cleaning materials and effluents generated.

- Installation of flow meters.

CETESB (2012)

Level 1-

- Wastewater treatment, to turn physical-chemical parameters in accordance with the launching standards established by CONAMA Resolution 430/2011.

CONAMA

Resolution

Brasil (2011)

- Replacement of detergents for alternative products, with less impact (vinegar and sodium bicarbonate). When it is not possible, dilute the detergent before the use

Machado

(2012)

- Training employees on the handle and transfer materials (in order to avoid product damage, loss of materials, accidents with chemicals), and consequently, more generation of solid waste and wastewater.

\section{Generation of atmospheric emissions}

- Cloister processes that emit volatile organic compounds or that generate pollutant particles (or source emitters).

CETESB (2012)

- Deployment of exhaust fans.

CETESB (2012)

Level 1-

Reduction at

- Route planning, load reduction unnecessary, vehicle fleet maintenance and tire pressure. This allows improving fuel consumption in the product distribution phase and consequently

Nunes et al. (2018) source releasing $\mathrm{CO} 2$ into the atmosphere less).

\section{Generation of solid waste}

- Reuse of plastic drum containers.

National Solid

- Acquisition of color trash cans

Waste Policy

to segregate waste.

Brasil (2010);

- Inspection of packing and caps before the filling process.

CETESB (2012)

- Separation of waste according to classification (NBR 10004:2004).

National Solid

Waste Policy 
- Implementation of a selective collection system and partnerships with waste pickers' cooperatives.

- Implementation of reverse logistics for packaging.

- Training employees on the handle and transfer materials (in order to avoid product damage, loss of materials, accidents with chemicals), and consequently, more generation of solid waste and wastewater.

Brasil (2010)

- Labeling with an automatic application, avoiding the use of selfadhesive labels (this would imply a faster labeling process, without the need for an operator occurring fewer label waste).

CETESB (2012)

Level 1-

Reduction at source

\begin{tabular}{lc} 
- Use of packaging with greater conditioning capacity. & $\begin{array}{c}\text { European } \\
\text { Commission (2018) }\end{array}$ \\
\hline & European \\
- Use of sustainable packaging with the practice of 3Rs (Reduce, & Commission (2018); \\
Reuse and Recycle), as well as biodegradable packaging. & CETESB (2012)
\end{tabular}

Level 2Internal recycling

Level 3 External recycling

- Acquisition of a more modern sealing machine. This will increase the efficiency of the packaging process, reducing the amounts of shavings (solid waste), as well as reducing the consumption of electricity. Or even resize the machine to losses and offcuts to a minimum.

Based on the critical points identified, 36 improvement strategies were suggested (Table 01), most of which are related to level 1 of intervention (reduction at source). Among all of the identified opportunities, 8 were related to the consumption of raw materials and other inputs, 11 to the generation of solid waste, 4 corresponded to the consumption of water, 4 related to energy consumption, 6 of the generation wastewater and a small fraction to atmospheric emissions (3 opportunities).

Thus, the consumption of raw materials was the aspect with identified critical points, and equally, more opportunities for improvement were linked. It is worth mentioning that some measures were common to different aspects.

The adoption of measures that can minimize the impacts caused by the productive activity, developing strategies for replacement, acquisition, reuse, among other available mechanisms, is an important issue since the processes are not independent and there is no production planning.

Regarding the consumption of raw materials, one of the points raised was used raw materials of non-renewable origin (for example, mineral oil). Many components used in personal care products are the target of growing environmental worrying (Cassani and Gramatica, 2015). The substitution of alternative raw materials should be considered, 
DOI: 10.14807/ijmp.v12i4.1345

especially in view of the current trend in the cosmetics market for "eco-friendly" products and the decline in the supply of petrochemical raw materials.

Mineral oils, for example, used in all cosmetic products of the company are originated from a mixture of hydrocarbons obtained from the purification process of petroleum (Carvalho and Barbieri, 2012).

Another aspect is the use of colorants and fragrances in formulations. These substances are important for the appearance of cosmetics and characteristic pleasant smell, but they can be associated with environmental and health problems. Thus, its exclusion is the most suitable to obtain more sustainable formulations (Bom et al., 2019).

There are many options for alternative raw materials, for example, the use of materials based on vegetable oils and biopolymers in the formulation of cosmetics. These ingredients can be replacing commercial polymers derived from petroleum which the chemistry process is not always safe or environmentally friendly (Okereke et al., 2015).

Second Yara-Varón et al. (2017), the vegetable oils present excellent natural properties such as global availability, biodegradability, as well as minors cost economics and environmental (low ecotoxicity). These properties confer advantages in the development of value-added products such as cosmetics.

Regarding natural polymers, a review study by Morin-Crini and Crini (2019) the authors highlight the use of chitosan, a biopolymer obtained from chitin, for applications in cosmetics, hygiene and personal care. Benabid and Zouai (2016) also investigated the application of biopolymers in the cosmetic segment. The review included advanced applications of natural polymers, including cellulose and chitosan. Chaiyana et al. (2018) investigated the fatty acid content and antioxidant and moisturizing effect of Camellia assamica seed oil, which can be a promising oil to use in cosmetic formulations.

Residues can also be used additionally in formulations of the cosmetic industry as ingredients. Ribeiro et al. (2013) assessed the feasibility of using the lipid fraction of Spent Coffee Grounds (SCG), which are the residue obtained from the treatment of coffee, in the development of new cosmetic formulations. This alternative presented characteristics functionally promising and with good acceptance by consumers, as well as to be a form recycle the wastes from the coffee industry.

These are just some options within several possibilities. However, as affirms Bom et al. (2019), the inclusion of organic ingredients or green chemicals in cosmetic formulations 
DOI: 10.14807/ijmp.v12i4.1345

require most research and assessment in relation to the safety, stability in its use and performance regard to consumer aesthetic requests. Although bring positive results, the environmental performance of the bio-based ingredient (natural by-product derived one) can be affected by the treatments needed to make it suitable for use as a cosmetic ingredient. Thus, it is important to adopt integrated environmental assessment methods, based on the life cycle, to ensure that chemical options respond to the need of reducing environmental impacts at all stages of the life cycle of cosmetics (Secchi et al, 2016).

According to Bom et al. (2019), the availability of environment-friendly raw materials has strengthened the cosmetics industry to move towards sustainable development. In this bias, another factor that has contributed is the promotion of the bioeconomy (Cosmetics Europe, 2012), with a great interest in replacing substances of fossil origin with renewable substances (Secchi et al. 2019). The replacement of the raw material directly contributes sustainability of the sector since actions are realized in this initial phase will reflect on the sustainability of the final product.

Partnerships with local suppliers (rural suppliers, such as traditional communities and family farmers for example) are also seen as an opportunity for linked improvement. This model reduces costs and affects environmental issues related to greenhouse gases (considering minor product transport distances), a relationship of partnership and co-construction with providers, valorization of local knowledge and good social and environmental practices (Carvalho and Barbieri, 2012).

Besides the ingredients used and the source of these products acquired, the magnitude of impacts is partially related to the size of the product. According to Camargo et al. (2019), the products with the highest impacts per unit are those with the greatest weight. However, it has not been evaluated in the context of this study, which requires additional research.

The generation of solid waste was mainly related to the processes in the filling and packaging process. Reduce the waste goes through the acquisition of the packing machine more modern (for increasing the efficiency of the packaging secondary process) or even resize the machine to losses into the minimum. In addition, the separation of other waste according to classification, implementation of a selective collection system and partnerships with waste pickers' cooperatives, as well as the implementation of reverse logistics for packaging are other actions that can be adopted. 
INDEPENDENT JOURNAL OF MANAGEMENT \& PRODUCTION (IJM\&P)

http://www.ijmp.jor.br

v. 12, n. 4, May-June 2021

ISSN: 2236-269X

DOI: 10.14807/ijmp.v12i4.1345

The use of biodegradable packaging and the practice of 3Rs (Reduce, Reuse and Recycle) were also reported. The reduction of waste generated in the production process and related to post-consumption is a crucial issue to achieve better environmental performance in the cosmetics sector, especially of packaging. This is important, not only under a sustainable perspective but also because it can be expensive to discard. In January 2018 the European Commission adopted a strategy that proposes to make all plastic packaging reusable or recyclable by 2030. In addition, innovative materials and alternative materials should be developed and used in packing (European Commission, 2018). Biopolymers or plastics of plant origin and other materials such as bamboo and wood fiber are also finding packaging applications (Bom et al., 2019). This should boost a new stance in the cosmetic sector.

This is due to the results found by studies and the consensus that exists regarding the impacts caused by packaging. Camargo et al. (2019), when assessing the environmental impacts of ten cosmetic products in a Brazilian company, identified that the main impacts were concentrated on the extraction and production of ingredients and packaging, followed by the phase of use that requires water and energy to use rinse products.

Although water consumption is relatively small, water is an essential component in cosmetics production (either in the preparation of the product or in the secondary process). Thus, the suggestions pointed can contribute to the best environmental performance in the industry. They are mainly related to the process of cleaning, across Good Manufacturing Practice. According to Gonçalves and Cerqueira (2018), the clean-in-place (CIP) technique is more efficient in terms of reducing water consumption in the manufacture of cosmetics comparing to other initiatives in cosmetics factories in Brazil. Other actions related to water use are rainwater harvesting and wastewater reuse (Cosmetics Europe, 2019b), as well as installing flow meters in the cosmetic manufacturing process.

Regarding the generation of effluents, it is advisable that the organization perform removal of the residues adhered to the walls of the equipment before washing (by means of mechanical) and make wastewater treatment through physical-chemical processes, chemical (for example coagulation followed by precipitation) before being sent to the treatment network municipal. However, the best in site wastewater treatment technique must be evaluated according to the characteristics of the effluent generated. This requires additional study.

Regarding atmospheric emissions, a suggests is that emitters processes (or source emitters) of volatile organic compounds or that generate particles go cloistered (CETESB, 
INDEPENDENT JOURNAL OF MANAGEMENT \& PRODUCTION (IJM\&P)

http://www.ijmp.jor.br

v. 12, n. 4, May-June 2021

ISSN: 2236-269X

DOI: 10.14807/ijmp.v12i4.1345

2012). Second Vargas-Gonzalez et.al (2019), among other indicators, the level of concentrations acceptable particulate matter (PM) increase the quality of the ecosystem and preserving human health internal (employees) and external (local community).

The greenhouse gas emissions reduction focused on product distribution thought route planning, unnecessary load reduction, vehicle fleet maintenance and tire pressure. This allows to improve fuel consumption in the product distribution phase and consequently release of $\mathrm{CO} 2$ into the atmosphere less. Once the sector is adapting its distribution practices to reduce emissions associated with cosmetics transport (Cosmetics Europe, 2019b), these actions can be required in the future from customers.

Another important issue, not yet mentioned, is the changes in employee behavior. Training and capacity building are tools that can be used aiming to raise awareness of environmental issues and cleaner practices. Xanthos and Walker (2017), state that education has been one of the best strategies to mitigate the negative impacts at the source because while awareness grows, pollution decreases.

It is worth mentioning that the recommended strategies may be different between companies (vary according to size, level of technology used, for example). The changes are mainly aimed at optimizing the cleaning process, reducing water consumption; production planning in batches (cosmetics sequence production that uses the same equipment can economy washing steps); replacement of old equipment with new ones; installation of electrical devices with low energy consumption (for example, pumps, extruders); and "energy recycling” (Cosmetics Europe, 2012).

Some suggestions for improvement are common in CP studies. They are opportunities that do not depend on the manufacturing type of product and they are applicable to different realities (civil construction, food industry, textile sector, for example). They are mainly related to energy consumption, such as searching for more sustainable alternative energy sources, turning off equipment and machines when they are not in use and installing lamps with sensors, for example. The practices of 3R's (Reduce, Reuse and Recycle), as well as using biodegradable packaging are also suggestions that can be applied in other types of industry.

The sustainable practices adopted by the cosmetics industries can be a business successful opportunity and more viable in the long term since this is a new beauty trend (Secchi et al., 2019). It's the case of Natura, for example. The company shows a culture of valuation and the insertion of sustainability in its business model, for its behavior toward the sustainable 
INDEPENDENT JOURNAL OF MANAGEMENT \& PRODUCTION (IJM\&P)

http://www.ijmp.jor.br

v. 12, n. 4, May-June 2021

ISSN: 2236-269X

DOI: $10.14807 /$ ijmp.v12i4.1345

use of biodiversity, which allowed its recognition in Brazil and abroad. As an example of implemented actions, it can be mentioned formulations that use plant products, preference for use of renewable raw materials; use biodiversity assets whose origin can be traced or is certified (such organic farming or sustainable forest management) and packaging that prioritize renewable materials or post-consumption recycled materials (Carvalho and Barbieri, 2012).

Recognition of aspects and identification of critical points is crucial in this process. According to Camargo et al. (2019), critical points are useful for considering alternative processes, materials, or suppliers to reduce the impacts of your supply chain. In relation to the suppliers, efforts to manage global impacts depend on the choice of these and their commitment to reducing their own environmental footprint, together with consumer awareness.

Second Carvalho and Barbieri (2012), the analysis of the induction of social and environmental practices by a Brazilian focal company of cosmetics, the incorporation of a sustainable business model is possible when the company aligns its strategic sustainability objectives with its power of innovation and involves direct and indirect suppliers, in addition to developing new partners in its initiatives to find innovation in products and processes.

It is known that for the purchase of green cosmetics several factors have great importance (the health consciousness, environmental concern, social factors, ecolabel, environmental knowledge and price). However, second Liobikienė and Bernatonienė (2017), the behavior of purchasing cosmetics is scarcely analyzed. The authors reviewed 80 studies on consumer green purchase behavior and only 11 were on cosmetics.

The identification, selection and implementation of the CP opportunities can increase the reliability of the process of decision making. However, the implementation of CP procedures can face economic, environmental and technological barriers (Oliveira et al., 2016). Second Nunes et al. (2019), despite its benefits, the CP practices have low application rates in small and medium-sized enterprises which are attributed to barriers such as a lack of resources, concentrated decision-making by owners and lack of leadership.

This is an aspect to be taken into account since many companies do not have the cash flow to implement actions that require greater investment. However, it is important to note that other many actions are simple and can generate a positive result in a low time, such as employee training, awareness for good environmental practices and reducing the consumption of the resources. Specific credit lines (targeted to companies with sustainable practices) can assist to get new equipment and replacement of machinery for more modern others. 


\section{CONCLUSIONS AND RECOMMENDATIONS}

The study made it possible to understand the production process of the cosmetics factory and how the organization is positioned about environmental issues. Practices and programs aimed at the environment no are used or were implanted.

The organization has a medium polluting potential, due to the type of raw materials used, high-energy consumption and a large amount of generated solid waste.

Among the proposed alternatives, a large number were directed to level 1 of intervention (reduction at source) as from the substitution of raw materials, implementation of the good manufacturing practices (housekeeping), dissemination of the environmental culture, as well as technological changes.

The improvement opportunities presented can result in gains in productivity, avoid wasting material and rework. In addition, it serves as a subsidy and directs environmentally appropriate actions, contributing to the adoption of a more responsible and committed attitude by the organization.

In addition, environmentally responsible customers can request them at some moment, since the "clean beauty industry" seems to be a growing trend and a business opportunity.

\section{REFERENCES}

ABIHPEC - Associação da Indústria de Higiene Pessoal, Perfumaria e Cosméticos (2019). Anuário 2019, p. 1-120. https://abihpec.org.br/anuario-2019/mobile/index.html\#p=1

Bai, Y., Yin, J., Yuan, Y., Guo, Y., Song, D. (2015). An innovative system for promoting cleaner production: mandatory cleaner production audits in China. Journal of Cleaner Production, 108, 883-890. doi:10.1016/j.jclepro.2015.07.107

Barbosa, F. A. N. (2018). Segurança do Trabalho e Gestão Ambiental, 5 ed., São Paulo: Editora Atlas.

Benabid, F. Z., Zouai, F. (2016). Natural polymers: cellulose, chitin, chitosan, gelatin, starch, carrageenan, xylan and dextran. Algerian Journal of Natural Products, 4(3), 348-357. http://doi.org/10.5281/zenodo.199036

Bom, S., Jorge, J., Ribeiro, H. M., Marto, J. (2019). A Step Forward on Sustainability in the Cosmetics Industry: a review. Journal of Cleaner Production, 225, 270-290. doi:10.1016/j.jclepro.2019.03.255

Brasil (1976). Lei n ${ }^{0}$ 6.360, de 23 de setembro de 1976. Dispõe sobre a Vigilância Sanitária a que ficam sujeitos os Medicamentos, as Drogas, os Insumos Farmacêuticos e Correlatos, Cosméticos, Saneantes e Outros Produtos, e dá outras Providências. Diário Oficial da União. 
DOI: $10.14807 /$ ijmp.v12i4.1345

Brasil (2010). Lei $\mathrm{n}^{\circ}$ 12.305, de 02 de agosto de 2010. Institui a Política Nacional de Resíduos Sólidos; altera a Lei no 9.605, de 12 de fevereiro de 1998; e dá outras providências. Diário Oficial da União.

Brasil (2011). Resolução CONAMA 430, de 13 de maio de 2011. Dispõe sobre as condições e padrões de lançamento de efluentes, complementa e altera a Resolução no 357, de 17 de março de 2005, do Conselho Nacional do Meio Ambiente-CONAMA. Diário Oficial da União.

Camargo, A. M., Forin, S., Macedo, K., Finkbeiner, M., Martínez-Blanco, J. (2019). The implementation of organizational LCA to internally manage the environmental impacts of a broad product portfolio: an example for a cosmetics, fragrances, and toiletry provider. The International Journal of Life Cycle Assessment, 24, 104-116. doi:10.1007/s11367-0181502-4

Carvalho, A., Barbieri, J.C. (2012). Innovation and sustainability in the supply chain of a cosmetics company: a case study. J. Technol. Manag. Innov. 7, 144-156. doi.org/10.4067/S0718-27242012000200012

Cassani, S., Gramatica, P. (2015). Identification of potential PBT behavior of personal care products by structural approaches. Sustainable Chemistry and Pharmacy, 1, 19-27. doi:10.1016/j.scp.2015.10.002

CEPRAM - Conselho Estadual do Meio Ambiente (2018). Resolução CEPRAM No 4.579, de 06 de março de 2018. SEMA/CEPRAM, Bahia.

CETESB - Companhia Ambiental do Estado de São Paulo (2012). Guia Técnico Ambiental da Indústria de Higiene Pessoal, Perfumaria e Cosméticos - Por uma produção mais limpa. Apostila: São Paulo, p. 68. https://abihpec.org.br/site2019/wpcontent/uploads/2012/07/higiene.pdf.

Chaiyana, W., Leelapornpisid, P., Jakmunee, J., Korsamphan, C. (2018). Antioxidant and Moisturizing Effect of Camellia assamica Seed Oil and Its Development into Microemulsion. Cosmetics, 5(3), 40. doi:10.3390/cosmetics5030040

Cosmetics Europe (2012). The Personal Care Association. Good Sustainability Practice (GSP) for the Cosmetics Industry. Cosmetics Europe - The Personal Care Association, p. 32. https://www.cosmeticseurope.eu/files/4214/6521/4452/GSP_Brochure.pdf.

Cosmetics Europe (2019a). The personal care association. Cosmetics and personal care industry overview. https://cosmeticseurope.eu/cosmetics-industry.

Cosmetics Europe (2019b). Environmental Sustainability. The European Cosmetics Industry's contribution 2017-2019.

https://cosmeticseurope.eu/files/3715/6023/8402/Environmental_Sustainability_Report_2019 .pdf

COSMOS-standard - Cosmetics Organic and Natural Standard (2019). Brussels: European Cosmetics Standards Working Group, p. 1-47, Belgium. https://cosmosstandard.files.wordpress.com/2018/12/COSMOS-standard-V3.0-includingeditorial-changes-0101_2019.pdf

Denham, F. C., Howieson, J. R., Solah, V. A., Biswas, W. K. (2015). Environmental supply chain management in the seafood industry: past, present and future approaches. Journal of Cleaner Production, 90, 82-90. doi:10.1016/j.jclepro.2014.11.079 
Europe Comission (2018). A European Strategy for Plastics in a Circular Economy. https://ec.europa.eu/environment/circular-economy/pdf/plastics-strategy-brochure.pdf.

Filho, J. C., Nunhes, T. V., Oliveira, O. J. (2019). Guidelines for cleaner production implementation and management in the plastic footwear industry. Journal of Cleaner Production, 232, 822-838. doi:10.1016/j.jclepro.2019.05.343

Galembeck, F., Csordas, Y. (2011). Cosméticos: a química da beleza. Coordenação Central de Educação a Distância. http://web.ccead.pucrio.br/condigital/mvsl/Sala\%20de\%20Leitura/conteudos/SL_cosmeticos.pdf

Gonçalves, S., Cerqueira, C. R. (2018). Analysis of Water Consumption in Cosmetic Factories in Brazil. New Global Perspectives on Industrial Engineering and Management, 269-271. doi:10.1007/978-3-319-93488-4_30

Liobikienè, G., Bernatonienè, J. (2017). Why determinants of green purchase cannot be treated equally? The case of green cosmetics: Literature review. Journal of Cleaner Production, 162, 109-120. doi:10.1016/j.jclepro.2017.05.204

Machado, A. A. (2012). Dos primeiros aos segundos doze princípios da Química Verde. Química Nova, 35(6), 1250-1259.

Matos, L. M., Anholon, R., Da Silva, D., Cooper Ordoñez, R. E., Gonçalves Quelhas, O. L., Filho, W. L., De Santa-Eulalia, L. A. (2018). Implementation of cleaner production: A tenyear retrospective on benefits and difficulties found. Journal of Cleaner Production, 187, 409-420. doi:10.1016/j.jclepro.2018.03.181

Morin-Crini, N., Lichtfouse, E., Torri, G., Crini, G. (2019). Applications of chitosan in food, pharmaceuticals, medicine, cosmetics, agriculture, textiles, pulp and paper, biotechnology, and environmental chemistry. Environmental Chemistry Letters. doi:10.1007/s10311-01900904-X

Nunes, J. A. R., Bonilla, S. H., Da Silva, H. R. O., Bueno, R. E. (2018). Cadeia de suprimentos e as práticas sustentáveis: uma proposta para o setor cosmético. Iberoamerican Journal of Project Management, 9(2), 118-136.

Nunes, J. R. R, Silva, J. E. A. R., Moris, V. A. S., Giannetti, B. F. (2019). Cleaner Production in small companies: proposal of a management methodology. Journal of Cleaner

Production, 218, 357-366. doi:10.1016/j.jclepro.2019.01.219

Okereke, J. N., Udebuani, A. C., Ezeji, E. U., Onasi, K., Nnoli, M. C. (2015). Possible health implications associated with cosmetics: a review. Sci. J. Public Heal. 3, 58. https://doi.org/10.11648/j.sjph.s.2015030501.21

Oliveira, J. A., De, Oliveira, O. J., De, Ometto, A. R., Capparelli, H. F. (2016). Guidelines for the integration of EMS based in ISO 14001 with Cleaner Production. Production, 26(2), 273-284. doi:10.1590/0103-6513.160214

Ribeiro, H., Marto, J., Raposo, S., Agapito, M., Isaac, V., Chiari, B. G., Simões, P. (2013). From coffee industry waste materials to skin-friendly products with improved skin fat levels. European Journal of Lipid Science and Technology, 115(3), 330-336. doi:10.1002/ejlt.201200239

Secchi, M., Castellani, V., Collina, E., Mirabella, N., Sala, S. (2016). Assessing ecoinnovations in green chemistry: Life Cycle Assessment (LCA) of a cosmetic product with a bio-based ingredient. Journal of Cleaner Production, 129, 269-281. doi:10.1016/j.jclepro.2016.04.073 
DOI: $10.14807 /$ ijmp.v12i4.1345

SEI - Superintendência de Estudos Econômicos e Sociais da Bahia (2015). Perfil dos Territórios de Identidade da Bahia. Publicações SEI. Salvador.

UNEP - United Nations Environment Programme (1994). Produção mais limpa no mundo $2^{a}$ Edição, Paris.

Vargas-Gonzalez, M., Witte, F., Martz, P., Gilbert, L., Humbert, S., Jolliet, O., L'haridon, J. (2019). Operational Life Cycle Impact Assessment weighting factors based on Planetary Boundaries: Applied to cosmetic products. Ecological Indicators, 107, p. 105498. doi:10.1016/j.ecolind.2019.105498

Xanthos, D., Walker, T. R. (2017). International policies to reduce plastic marine pollution from single-use plastics (plastic bags and microbeads): a review. Marine pollution bulletin, 118(1-2), 17-26. doi.org/10.1016/j.marpolbul.2017.02.048

Yara-Varón, E., Li, Y., Balcells, M., Canela-Garayoa, R., Fabiano-Tixier, A.-S., Chemat, F. (2017). Vegetable Oils as Alternative Solvents for Green Oleo-Extraction, Purification and Formulation of Food and Natural Products. Molecules, 22(9), 1474.

doi:10.3390/molecules22091474 